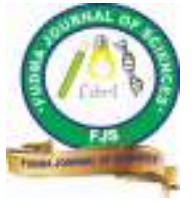

Vol. 4 No. 2, June, 2020, pp $478-489$

DOI: https://doi.org/10.33003/fjs-2020-0402-140

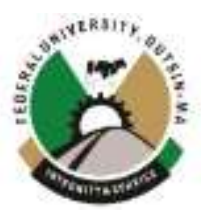

\title{
RENIN-INHIBITORY BIOACTIVE PEPTIDES WITH ANTIHYPERTENSIVE PROPERTY: A REVIEW
}

\author{
"Sanusi Bello Mada, Chizoba Paul Ugwu, Muawiya Musa Abarshi, and Muhammad Auwal Saliu \\ Department of Biochemistry, Ahmadu Bello University Zaria, Nigeria. \\ *Corresponding author's E-mail address: sbmada@abu.edu.ng
}

\begin{abstract}
Blood pressure is regulated by the renin angiotensin aldosterone system (RAAS). Renin-catalyzes the conversion of angiotensinogen to angiotensin I and is the rate-limiting step of the RAAS pathway, which arguably makes renin inhibitors more better target for prevention, treatment and management of hypertension than angiotensin-converting-enzyme (ACE) inhibitors. Enzymatic hydrolysis of food proteins releases bioactive peptides that can interact with receptors, enzymes and molecules in the organism to promote health. Several studies have shown that these bioactive peptides could be exploited for management of hypertension which is a major risk factor for cardiovascular diseases (CVDs). Antihypertensive peptides are bioactive peptides derived from plant and animal sources with inherent potential to ameliorate hypertension by different mechanisms including scavenging of free radicals, reduction of cholesterol level, inhibition of angiotensinconverting enzyme (ACE) and renin enzyme activities. Although there is a lot of sufficient information on ACE-inhibitory and antioxidative peptides while literature on the potential role of renin-inhibitory peptides in the treatment of hypertension is limited. Thus, herein the present review primarily used ISI, SCOPUS and PubMed indexed journals containing experimental reports to elucidate the potential role of bioactive peptides in the management of hypertension through inhibition of rennin activity.
\end{abstract}

Keywords: Hypertension; Bioactive peptides; Renin inhibition; Mechanism of action.

\section{INTRODUCTION}

Blood pressure is simply defined as quantitative expression of the pressure in large arteries of the systemic circulation. The normal blood pressure for an individual is about $120 / 80 \mathrm{~mm} \mathrm{Hg}$ while blood pressure which persistently exceeds 140/90 mm Hg is considered hypertensive. Hypertension is a risk factor for cardiovascular disease and stroke which in turn is one of the leading causes of death across the world (Nawaz et al., 2017). Due to its asymptomatic nature coupled with lackadaisical attitude of some patients towards health and well-being, many hypertensive patients are not aware of it (Vincent-Onabajo et al., 2017). Blood pressure is mainly controlled by renin angiotensin aldosterone system (RAAS). The RAAS pathway involves renin-catalyzed convertion of angiotensinogen to angiotensin I. Angiotensin I is then converted to angiotensin II via the action of angiotensin-converting enzyme (ACE). Angiotensin II mediates vasoconstriction and activates aldosterone release from adrenal gland (Nawaz et al., 2017). Aldosterone promotes the expression of epithelial sodium channels which leads to sodium and water reabsorption resulting in the increased blood pressure (Nawaz et al., 2017). In addition, oxidative stress was linked to hypertension particularly when the level of reactive oxygen species (ROS) exists in excess of antioxidant defense capacity of cells. In a physiological system, the imbalance between antioxidant defense mechanism and ROS production leads to oxidative stress and subsequent pathological conditions due to cellular injury [Heitzer et al., 2001). ROS formation is associated with endothelial dysfunction, which is a key feature of cardiovascular diseases, including hypertension, atherosclerosis, and diabetes mellitus (Bedard et al., 2007). A previous study reported that ROS can oxidize low density lipoproteins leading to endothelial dysfunction which contributes to the formation of atherosclerotic plaque thereby increasing the likelihood of hypertension (Paudel et al., 2016). There are plethoras of evidences linking the prevalence of hypertension to lifestyle and dietary factors (Daliri et al., 2017; Gul et al., 2015; HernándezLedesma et al., 2011). Consequently, functional foods are emerging in response to the increased perception among consumers about the relationship between food and health benefits. In the past three decades, researchers have spent time and resources on the search for antihypertensive agents from potential natural antihypertensive agents in order to reduce the dependency on commercially available synthetic antihypertensive drugs often associated with negative side effects (Lin et al., 2018). Food proteins can be enzymatically hydrolysed to produce bioactive peptides with antihypertensive potential (Ugwu et al., 2019; Mada et al., 2019). Bioactive peptides are active fragments contained in parent protein (Reddi et al., 2016), but remain inactive until the parent protein is hydrolysed by cellular proteases (Hernández-Ledesma et al., 2014; Mada et al., 2017a), individually or combined (Mohanty

FUDMA Journal of Sciences (FJS) Vol. 4 No. 2, June, 2020, pp 478 - 489 
et al. 2016; Kumar et al., 2016; Bamdad et al., 2017; Chaudhari et al., 2017) and also by microbial fermentation (Palaniswamy et al., 2012; Koyama et al., 2014; García-Tejedor et al., 2015; Aguilar-Toalá et al., 2017; Yahya et al., 2017) or gastrointestinal digestion (Hernandez-Ledesma et al., 2011; Alvarado et al., 2019). Antihypertensive peptides are bioactive peptides derived from plant and animal sources with inherent potential to ameliorate hypertension through antioxidative effect and scavenging of free radicals ( Mada et al., 2017b; Lassoued et al., 2015., Panth et al., 2016; Wang et al., 2017; Basilicata et al., 2018; Pachaiappan et al., 2018; Ugwu et al., 2019), lowering of blood cholesterol level (Lammi et al., 2016; Hernandez and de-Mejia, 2017), inhibition of ACE activity (HernandezLedesma et al., 2014; Capriotti et al., 2015; Korczek et al., 2018; Mirzaei et al., 2018; Ugwu et al., 2019) or inhibition of renin enzyme activity (Aluko, 2019; Lin et al., 2017). Many research findings have continuously confirmed the antihypertensive effect of bioactive peptides and there is a lot of sufficient information on ACE-inhibitory and antioxidative peptides while literature on the potential role of renin-inhibitory peptides in the treatment of hypertension is limited. Renincatalyzed conversion of angiotensinogen to angiotensin I and is the rate-limiting step of the RAAS pathway which makes renin inhibitors more better target for treatment and management of hypertension than ACE. Moreover, excessive plasma level of angiotensin $\mathrm{I}$ is a causative factor for hypertension because angiotensin $\mathrm{I}$ is the substrate used by ACE to produce angiotensin II, a vasoconstrictor (Fyhrquist \& Saijonmaa, 2008). Therefore, bioactive peptides with renin-inhibitory effect can potentially lower blood pressure and provide relief from negative side effects associated with synthetic drugs. Consequently, the present review employed ISI, SCOPUS and PubMed indexed journals containing experimental reports to elucidate the potential role of bioactive peptides in the treatment of hypertension via inhibition of renin enzyme activity.

\section{DISCUSSION}

\section{Renin Angiotensin Aldosterone System}

The renin angiotensin aldosterone system (RAAS) plays a crucial role in the regulation of renal, cardiac and vascular physiology as well as the activation of hypertension (Ghazi and Drawz, 2017). Among the physiological mechanisms of hypertension, RAAS has attracted much scientific attention (Fig. 1). However, renin and ACE are the main enzymes involved in RAAS pathway (Guang et al., 2012). For example once the kidney detects a drop in blood pressure, it secrets renin which in turn catalyses the conversion of angiotensinogen to angiotensin I, one of the substrates for ACE. Then ACE catalyses the conversion of angiotensin I to angiotensin II, a vasoconstrictor (Nawaz et al., 2017). Angiotensin II promotes hypertension by increasing systemic vascular resistance and stimulating aldosterone release from the adrenal gland (Nawaz et al., 2017). Renin is first synthesized as preprorenin in the juxtaglomerular epithelioid cells, then signal peptide is removed by peptidase and preprorenin is converted to prorenin, an inactive form (Fig. 1). Like pepsinogen prorenin is activated by low $\mathrm{pH}$ and inactivated at neutral $\mathrm{pH}$. Prorenin is then proteolytically converted into active renin by plasma kallikrein in a process known as proteolytic activation (Fig. 1), and then is stored in granules (Derkx et al., 1987; Ames et al., 2019). The release of renin granules is strictly regulated, making renin the rate-limiting step of the RAAS pathway in most species (Ames et al., 2019). The ACE released from endothelial cells, converts angiotensin I to angiotensin II, then Angiotensin II acts at 2 different receptors; the angiotensin type- 1 and type- 2 receptors (AT-1R and AT-2R).Thus, the action of angiotensin II at the AT-1 receptor is responsible for increased sodium retention, vasoconstriction, increased salt consumption and aldosterone release from the adrenal gland of zona glomerulosa (Ames et al., 2019). The interaction of angiotensin II at this receptor causes some of the diseases associated with chronic RAAS activation. Additionally, while AT-2 receptor is beneficial in the development of fetus, it is less relevant in healthy adults. Its stimulation leads to anti-inflammatory, anti-fibrotic, and vasodilatory effects and it might be upregulated in certain disease conditions (De-Mello, 2015; De-Mello and Frohlich, 2014; Bader, 2013). Aldosterone is an adrenal steroid hormone that binds to the mineralocorticoid receptors of the distal convoluted tubule. It increases the expression of epithelial sodium channels resulting in sodium and water reabsorption and possible hypertension (Briet and Schiffrin, 2010). Also, aldosterone mediates most of the mineralocorticoid activity of adrenal secretions, and regulates sodium, potassium, and body fluid balance (Hall and Guyton, 2010; Seelinger et al., 2005). In addition, angiotensin II and increased extracellular $\mathrm{K}^{+}$ concentration, amplify expression of the CYP11B2 gene which encodes aldosterone synthase (Beuschlein, 2013). Aldosterone in turn acts via the mineralocorticoid receptor thereby modulating the expression of ion channels, pumps, and exchangers in epithelial tissues (Ames et al., 2019). This leads to increased transepithelial $\mathrm{Na}^{+}$and water reabsorption as well as $\mathrm{K}^{+}$excretion. Interestingly, mineralocorticoid receptors are present in non-epithelial tissues such as the retina, vascular smooth muscle cells, macrophages, brain, myocardium, adipocytes and fibroblasts (Jaisser et al., 2015; Marzolla et al., 2014; Marzolla et al., 2012; Funder et al., 1989; Funder et al., 1988). Aldosterone specifically mediates inflammation and affects energy metabolism in non-epithelial tissues (Marzolla et $a l ., 2014)$. Angiotensin peptides and aldosterone are equally synthesized in brain, blood vessels, kidneys, and the heart (DeMello and Frohlich, 2014; Bader, 2010; Bader and Ganten, 2008; Dzau et al., 2001). They play important roles in normal cardiovascular function and electrolyte-fluid homeostasis. However, they equally mediate abnormal remodeling in the tissues (Ames et al., 2019). In-vitro experiment on cultured vascular smooth muscle cells and cardiomyocytes indicates that aldosterone upregulates ACE activity and angiotensin IIstimulated signal transduction, leading to increased tissue

FUDMA Journal of Sciences (FJS) Vol. 4 No. 2, June, 2020, pp 478 - 489 
activity of the RAAS (Harada et al., 2001; Ullian et al., 1994; Ullian et al., 1993; Ullian et al., 1992). Gradual and continuous activation of RAAS promotes and perpetuates heart failure, systemic hypertension, and chronic kidney disease (Ames et al., 2019). Understanding the role of the RAAS in hypertension has grown over the past few decades and numerous therapeutic strategies aimed at blocking key components of the RAAS pathway have been developed. Many synthetic antihypertensive drugs have been reported to cause adverse effects such as dizziness, dysgeusia, headache, angioedema, and cough (Daliri et al., 2016), which has prompted the growing demand for antihypertensive peptides from food sources particularly due to their health-promoting effect and safety (Daliri et al., 2017).

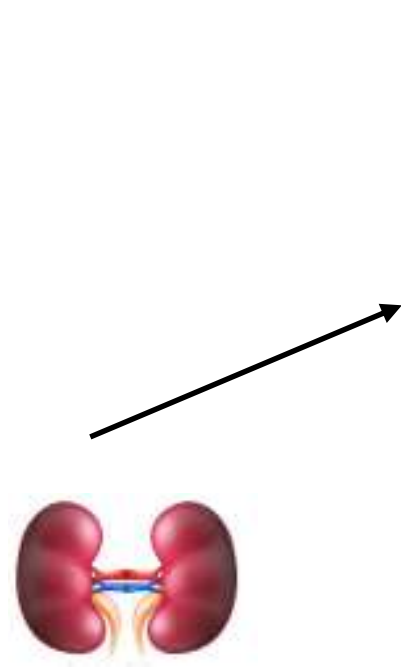

(Detect fall in blood pressure)
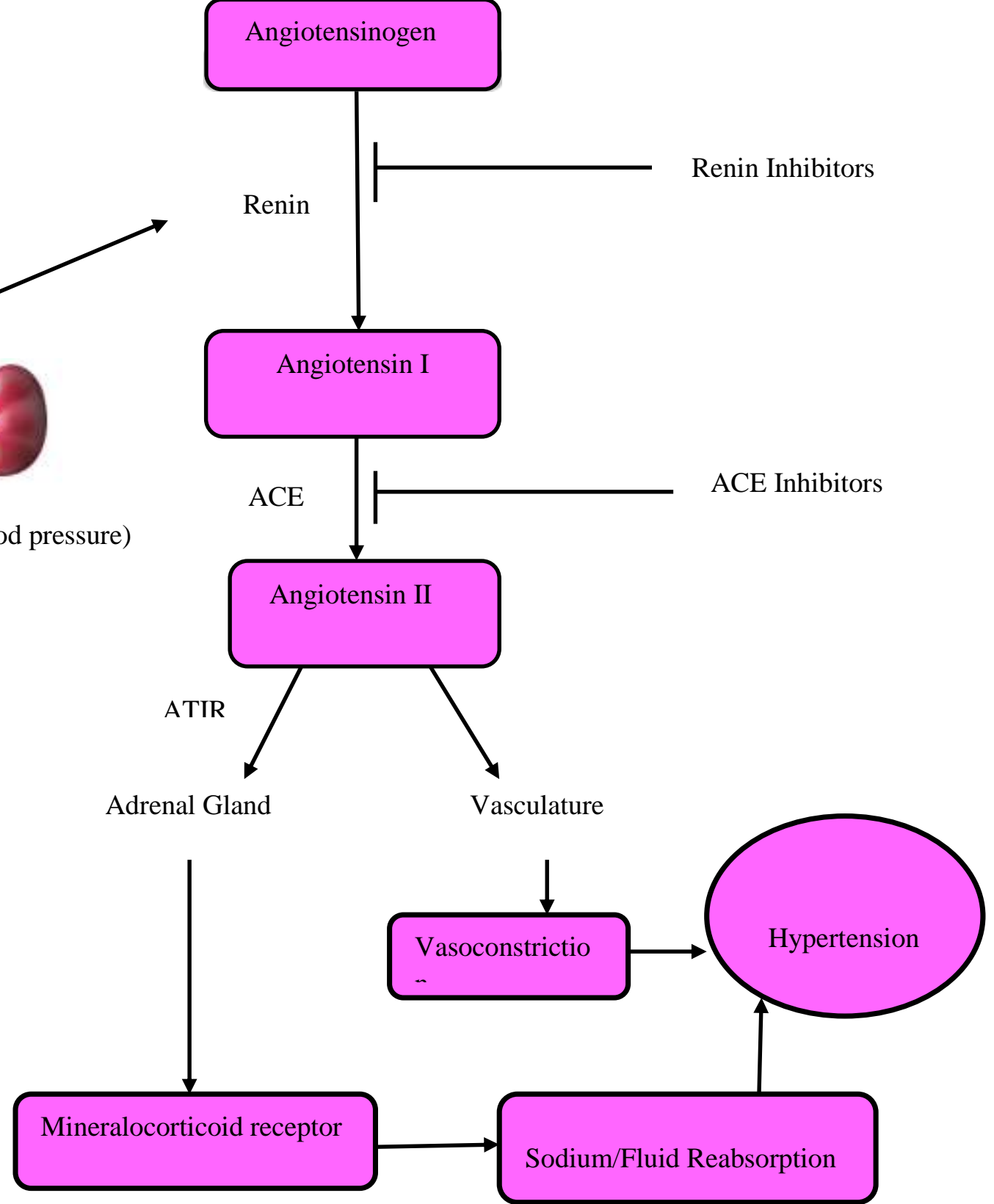

Figure 1: Renin angiotensin aldosterone system (RAAS) and its role in the regulation of blood pressure and hypertension. ATIR = Angiotensin type -1 receptor; ACE = Angiotensin Converting Enzyme.

\section{Antihypertensive Peptides}

Enzymatic hydrolysis or microbial fermentation of protein releases a large variety of bioactive peptides which can mimic peptide sequences acting in the organism as endogenous signals, or hormones (Hernández-Ledesma et al., 2014). Generally, these bioactive peptides have high tissue affinity, specificity and efficiency, they can interact with enzymes and certain molecules in the organism to exhibits their primary function (Reddi, et al., 
2019; Mada et al., 2019). The inherent physico-chemical characteristics of amino acid residues in the peptide sequences are responsible for their antihypertensive properties (Ugwu et al., 2019). Antihypertensive peptides (Fig. 2) can act through inhibition of ACE and renin activity (Bleakley et al., 2017; Zou et al., 2016; Daliri et al., 2017; Ugwu et al., 2019), lowering of cholesterol level in the blood, prevention of oxidative damage and atherosclerosis thereby lowering blood pressure (Mada et al., 2019) as outlined in (Fig. 2). Therefore, bioactive peptides with potential antihypertensive effect are gaining interest mainly due to lack of obvious adverse effects compared to orthodox antihypertensive drugs. Although, a previous study has shown that some bioactive peptides released by enzymatic hydrolysis or microbial fermentation can be potentially toxic or allergic (Liu et al., 2020). Notwithstanding, bioactive peptides has been regarded as safe could be potentially employed for treatment and management of hypertension. Based on available literature a lot of studies on antihypertensive peptides focused on ACE inhibition while bioactive peptides with renin inhibition potential has been neglected despite the fact that it catalyzes the rate-limiting step of RAAS.

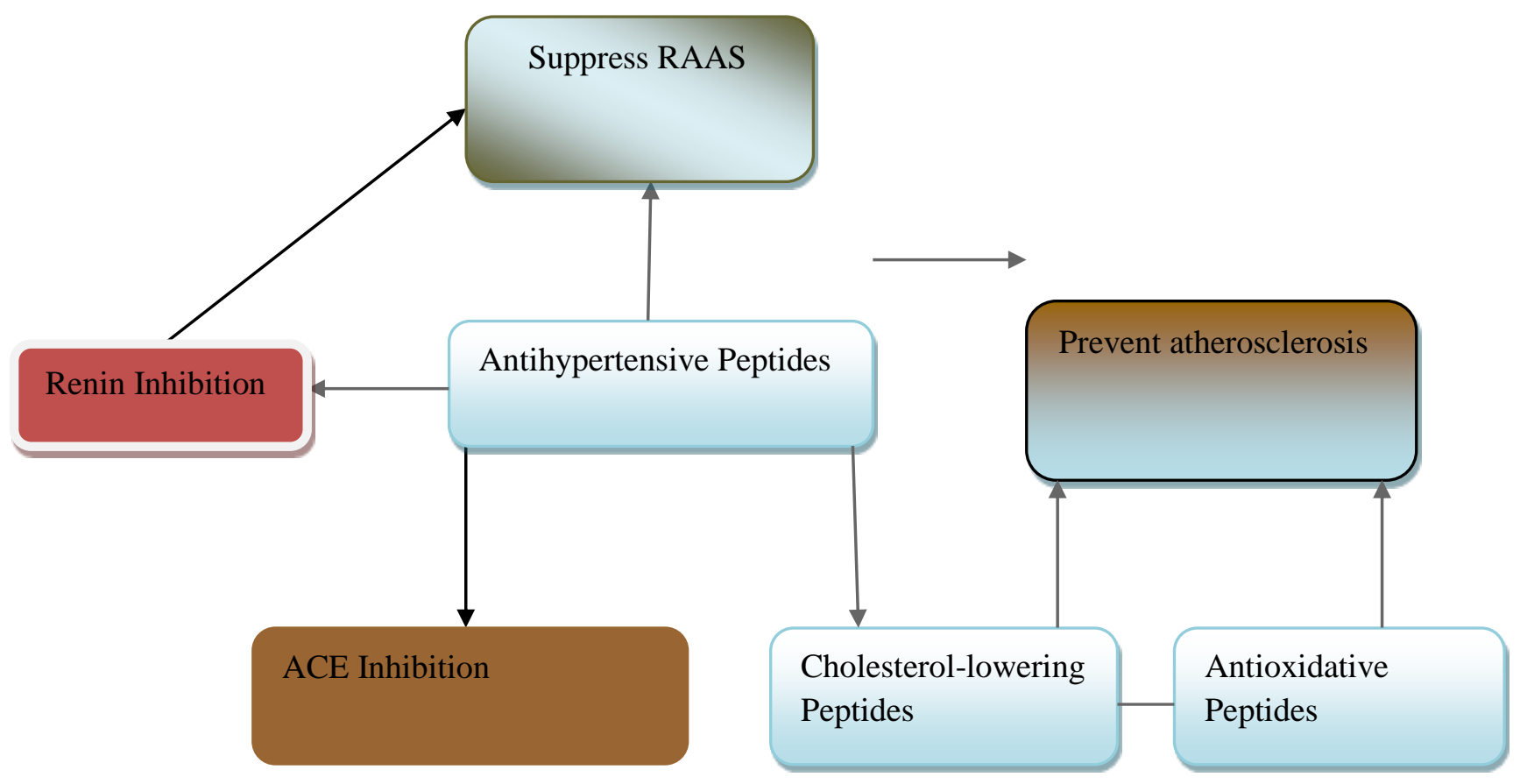

Figure 2: Different mechanisms through which bioactive peptides achieved antihypertensive effect. RAAS= Renin angiotensin aldosterone system, ACE $=$ Angiotensin Converting Enzyme .

\section{Renin Inhibitory Peptides}

The primary function of renin is therefore to cause an increase in blood pressure, leading to restoration of perfusion pressure in the kidneys when volume of blood or sodium levels in the body are low or blood potassium level is high, then cells in the kidney release the enzyme renin (Ames et al., 2019). The use of ACE inhibitor or in combination with other antihypertensive agents such as renin has always been considered the most effective blood pressure control measure. However, renin inhibition is potentially a better alternative for blood pressure regulation than ACE inhibition because unlike ACE, renin catalyzes the ratedetermining step in the RAAS pathway (Duprez, 2006), by conversion of angiotensinogen which is present in the liver to angiotensin I. Then ACE found in the lungs metabolizes angiotensin I into angiotensin II. Subsequently angiotensin II causes blood vessels to constrict and thus leading to an increase in blood pressure (Ames et al., 2019; Duprez, 2006). Moreover, ACE inhibitors and receptor blockers suppress the physiological negative feedback effect of angiotensin II on renin activity (Aluko et al., 2019). Therefore, suppression of angiotensin II by ACE inhibitors may result in the increased level of renin in blood thereby activating the RAAS pathway to produce more angiotensin II and consequently reduce the activity of ACE inhibitors (Chen et al., 2013). A Previous study has shown that oral administration of lactoferrin hydrolysate to spontaneouslyinduced hypertensive rats led to a reduction in plasma ACE activity but increased renin activity (Fernandez-Musoles et al., 2013). Also, an ACE-inhibitory peptide (IW) and captopril caused increased expression of renin mRNA but lowered ACE activity in spontaneously-induced hypertensive rats (Martin et 
al., 2015). This inverse relationship between ACE and renin activities could threaten the long-term health benefits of ACE inhibitors; hence co-administration of renin inhibitors may improve management of hypertension (Aluko et al., 2019). Therefore, this also suggests administration of renin inhibitor as a single pill might not produce better antihypertensive effects.

Purification of crude peptides and its effect on renin activity Crude peptides may show renin-inhibitory effect but the inhibitory activity increases with increase in purity of the crude peptides (Addar et al., 2019). Upon enzymatic hydrolysis of protein with suitable proteases, followed by inactivation of the proteolytic enzymes and subsequent centrifugation produces crude peptides or peptide hydrolysates (Kumar et al., 2016; Ugwu et al., 2019), which can exhibit greater inhibitory effect than the unhydrolyzed proteins. However, further purification of crude peptides or peptide hydrolysates via s reversed phaseHPLC and ultrafiltration with membrane filters $(<1$ to $3 \mathrm{KDa})$ techniques can generate fragments of bioactive peptides with greater inhibitory activity than crude peptides. Previous study by Ciau-Solis and coworkers enzymatically hydrolyzed Lima bean (Phaseolus lunatus) protein with one of two sequential enzymatic systems (pepsin-pancreatin or Alcalase®Flavourzyme $($ ), their findings revealed that membrane ultrafiltration of the hydrolysates produced fractions of different molecular weights and $>3 \mathrm{kDa}$ fraction of the pepsin-pancreatin hydrolysate had the highest ACE-inhibitory activity while the $>3 \mathrm{KDa}$ fraction of the Alcalase ${ }^{\circledR}$-Flavourzyme ${ }^{\circledR}$ hydrolysate had the highest renin-inhibitory activity in vitro (Ciau-Solis et al., 2018). Interestingly, they demonstrated that fractionation of hydrolysate using membrane filter of $3 \mathrm{kDa}$ enhanced renin inhibition when compared to the crude hydrolysates. For instance, alcalase-flavourzyme and pepsin-pancreatin hydrolysates showed $15.5 \%$ and $5.5 \%$ renin inhibitions respectively (Table 1 ), while further ultrafiltration with $<3 \mathrm{kDa}$ membrane filter the fractions obtained exhibited increased in renin-inhibitory effects from $13.7 \%$ to $31.7 \%$ (Ciau-Solis et al., 2018). This is suggestive of a weak synergistic action among peptides in the crude peptide hydrolysate, hence more purification via ultrafiltration led to enhanced activity (CiauSolis et al., 2018). The probable explanation to this observed effect could be due to lack of strong synergistic effects in the crude hydrolysate; hence membrane fractionation led to isolation of low molecular weight bioactive peptides with higher renin inhibitory activity than the hydrolysate or high molecular weight (Aluko et al., 2019).

Moreover, this data imply a single or individual pure peptide may exhibit better renin inhibitory activity than many peptides working together in a particular fraction due to antagonistic effect, which were ameliorated after ultrafiltration of the hydrolysate fraction into low molecular weight bioactive peptides. Though, in contrast to the above findings, Girgih and colleagues also investigated the antihypertensive effects of enzymatic hemp seed protein hydrolysate (HPH) and its peptide fractions. They digested hemp seed protein using sequential action of pepsin and pancreatic enzymes to mimic gastrointestinal digestion in human beings and the resultant HPH was separated by membrane ultrafiltration into peptide fractions with different sizes $(<1$ and $1-3 \mathrm{kDa})$. Their data demonstrated that the peptides act synergistically to produce more effective renin inhibition when present together in the $\mathrm{HPH}$ hydrolysate and fractionation of the peptides resulted in the reduction of renin and ACE inhibition effect due to loss of this synergistic effect, probably due to size-dependent partitioning of active peptides into different peptide groups (Girgih et al., 2011). Furthermore, scientists do investigate the inhibitory effect of an individual pure peptide by further purification using high performance liquid chromatography (HPLC) or other techniques like column chromatography or reversed phase high performance liquid chromatography (RPHPLC) (Bleakley et al., 2017). For instance, rapeseed protein hydrolysate produced using alcalase and its HPLC fractions (Table 1) showed strong inhibitions of renin activity (Table 1). Bioassay-guided purification led to isolation of renin inhibitory peptides, which were identified as TF, LY, and RALP as presented in Table 1 (He et al., 2013). These peptides exhibited in vitro and in vivo renin inhibitory activity. This study also indicated a potential role for arginine in enhancing renin inhibition by peptides, which is consistent with previous findings for pea peptides (Li \& Aluko, 2010). In vivo studies showed that oral administration of the peptides to hypertensive rats led to reductions in systemic blood pressure (SBP) with LY being the most active $(-26 \mathrm{mmHg})$ followed by RALP $(-16$ $\mathrm{mmHg}$ ) while $\mathrm{TF}$ had $-12 \mathrm{mmHg}$ (He et al., 2013) as outlined in Table 1. 
Table 1: Renin-Inhibitory Bioactive Peptides

\begin{tabular}{llll}
\hline Bioactive Peptide & Origin & Proteolytic Enzyme & Reference \\
\hline IR, EF, KF & Pea protein & Alcalase & Li and Aluko, 2010 \\
SVYT,WYT, IPAGV & Hemp seed protein & Pepsin + Pancreatin & Girgih et al., 2014 \\
IFFFL, FFG, WCY & Oat protein & pepsin + Ficin & Bleakley et al., 2017 \\
PFL, FLLA, WWK & Oat protein & pepsin + Ficin & Bleakley et al., 2017 \\
LY, RALP, GHS & Rape seed protein & Alcalase & He et al., 2019 \\
IRLIIVLMPILMA & Palmaria palmata & Papain & Li and Aluko, 2010 \\
HR, YR, HF, HLP & Bovine hemoglobin & Papain & Lafarga et al., 2016 \\
SLR & Bovine serum albumin & Papain & Lafarga et al., 2016 \\
YR, SLR & Bovine fibrinogen & Papain & Lafarga et al., 2015 \\
APPH, IIY, PPL, PPG, FFG, & Bovine and Porcine & Papain + Pepsin & + Lafarga et al., 2014 \\
IPP, LPP & hemoglobin, collagen and & Thermolysin & \\
& serum albumin & & \\
\hline
\end{tabular}

G = Glycine; $\mathrm{A}=$ Alanine; $\mathrm{P}=$ Proline; $\mathrm{V}$ = Valine; $\mathrm{L}=$ Leucine; $\mathrm{I}=$ Isoleucine; $\mathrm{M}=$ Methionine; $\mathrm{F}$ = Phenylalanine; $\mathrm{Y}=$ Tyrosine; $\mathrm{K}=$ Lysine; $\mathrm{R}=$ Arginine; $\mathrm{H}=$ Histidine; $\mathrm{S}=$ Serine; $\mathrm{T}=$ Threonine; $\mathrm{C}=$ Cysteine; $\mathrm{N}=$ Asparagine; $\mathrm{Q}=\mathrm{Glutamine} ; \mathrm{D}=$ Aspartate; $\mathrm{E}=$ Glutamate

\section{Mechanism of action of renin inhibitory peptides}

Renin-inhibitory peptides use different molecular mechanisms to inhibit renin activity. A previous study showed that rapeseed protein-derived peptides could cross Caco-2 intestinal cell monolayer (Fig. 3), intact and inhibit ACE and renin enzymatic activities (Yang et al., 2017). Also, the peptides significantly inhibited renin mRNA and renin protein production (Fig. 3). Moreover, in vivo evaluation of renin-inhibitory effect of pea protein hydrolysate indicated that it inhibited renal renin mRNA expression by about $50 \%$ in rats ( $\mathrm{Li}$ et al., 2011) while egg protein-derived peptide, RVPSL (Table 1), also decreased kidney renin mRNA expression (Yu et al., 2014). Furthermore, a protein hydrolysate was reported to exhibit in vivo renininhibitory effect via reduction of plasma renin mRNA expression thereby ameliorating hypertension (Li et al., 2011). Likewise the net cationic charge of amino acids in the peptide sequences facilitates peptide-dependent inhibition of renin activity (Aluko, 2019). Digestion of flaxseed protein hydrolysate produced fragments which showed potential renin inhibitory effect (Udenigwe et al., 2009) while enzymatic hydrolysis of pea protein using alcalase generated crude peptide which upon further purification by solid phase extraction (SPE) and reversed phase-HPLC produced renin inhibitory peptides, IR, EF and KF (Li \& Aluko, 2010) as shown in Table 1. The renin inhibitory effect exhibited by peptides (Table 1) may be attributed to the cationic property of the amino acids in the sequence owing to the fact that IR and KF each have positively charged amino acid residues compared to EF with negatively charged amino acids. Thus, the findings indicated that IR and KF showed stronger renin inhibitory activity than EF ( $\mathrm{Li} \&$ Aluko, 2010). Moreover, the molecular weight, location and nature of amino acid residues in the peptide sequence contributed a lot to its renin inhibitory effect (Udenigwe et al., 2012). For instance, the presence of low molecular-weight hydrophobic amino acid residues at the $\mathrm{N}$-terminal and high molecular weights amino acid residues at the C-terminal of bioactive peptides can enhance renin inhibition probably due to resistant to digestion by endogenous proteases and are easily absorbed in the intestine as they can easily cross the intestinal barrier and thus exhibited more potency (Udenigwe et al., 2012; Robert et al., 1999). In addition, study on the pattern of renin inhibitory peptides indicated the existence of an interaction between the peptides and the amino acid residues present in the active site of the renin enzyme (Onuh et al., 2015). For instance, renin inhibition kinetics revealed that peptides obtained from chicken skin hydrolysate inhibited renin activity by mixed-type inhibition mechanism, indicating that the peptides can bind to either active site or enzyme-substrate (ES) complex (Onuh et al., 2015). The kinetic analysis of hemp seed proteins hydrolysates also showed a mixed-type inhibitory pattern for the peptide fractions which also revealed that the peptides were not bound only to the active site of renin enzyme but also at the enzyme substrate (ES) complex (Girgih et al., 2011). The results obtained imply that electrostatic charge interactions may play a significant role in determining peptide interactions with renin active site because cationic peptides have lower affinity for amino acid residues in the renin active site when compared noncationic peptides because bioactive peptides containing amino acids with ionizable side chains such as Asp, Glu, His, Lys, and Arg, impart important functional properties and modulation of the charges on these peptides by $\mathrm{pH}$ and may result in significant changes in the bioactivity of these peptides due to denaturation (Girgih et al., 2011; Zhou and Pang, 2018). It is also important to note that a single peptide may exhibit an inhibitory pattern different from that observed using hydrolysates or fractions due to the presence of interfering peptides working together as inhibitors. For example, three potent renin-inhibitory peptides SVYT, WYT and IPAGV were isolated from hemp seed protein hydrolysate inhibited renin enzyme through uncompetitive inhibition mechanism Girgih et al., 2014), while molecular

FUDMA Journal of Sciences (FJS) Vol. 4 No. 2, June, 2020, pp 478 - 489 
docking analysis showed the existence of interactions between these peptides amino acid residues present in the active site of the enzyme (Girgih et al., 2014).

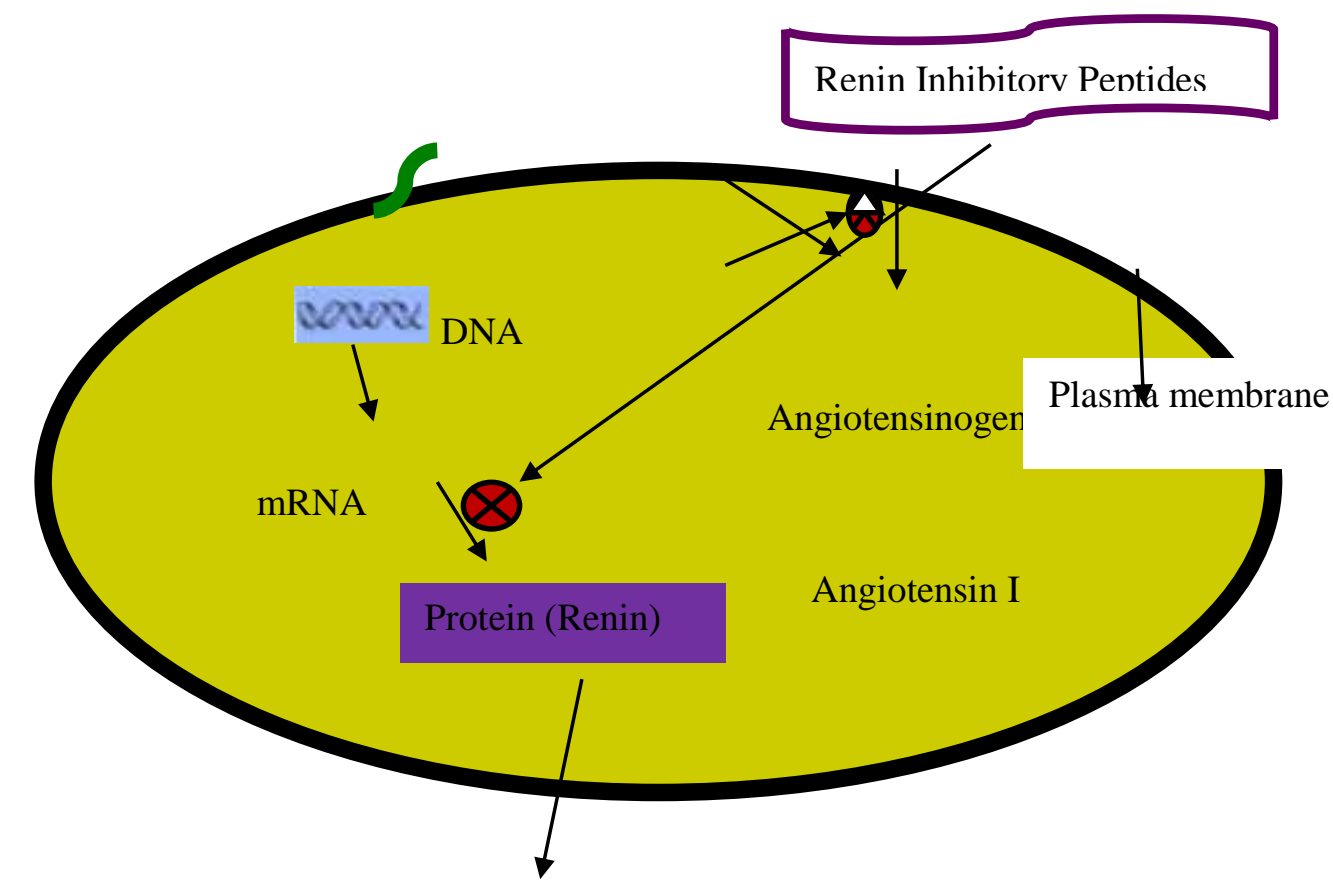

Antihypertensive Effect

hibition

Renin Angiotensin Aldosterone System (RAAS)

Angiotensinogen

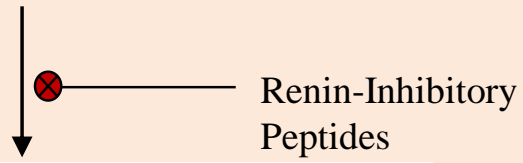

RAAS is suppressed leading to antihypertensive effect

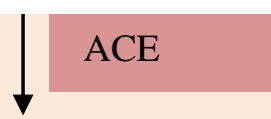

Angiotensin II (Vasoconstrictor)
Kinin-Kallikrein System (KKS)

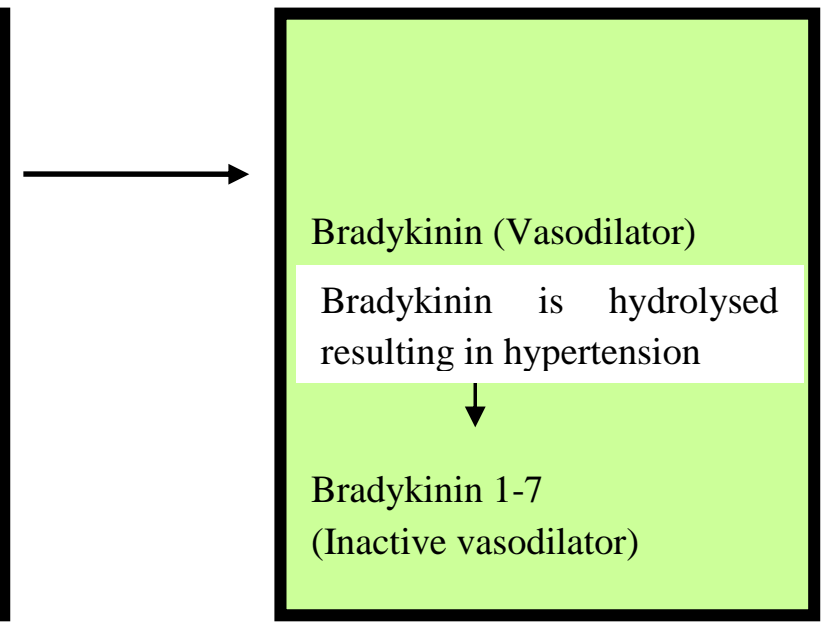

Figure 4: ACE uses KKS as an alternative pathway to activate hypertension

$$
\begin{aligned}
& =\text { Inhibition } \\
& =\text { Catalysis }
\end{aligned}
$$

Limitations of Renin Inhibitory Peptides

Since renin-catalyzed conversion of angiotensinogen to angiotensin I is the rate-limiting step of the RAAS pathway, this makes renin a better target than ACE for management of hypertension. However, ACE is a multifunctional enzyme that catalyzes the hydrolysis of bradykinin; a vasodilator to its 
inactive form, bradykinin 1-7 via the kinin-kallikrein system (KKS) (Imig, 2004), thereby promoting vasoconstriction and possibly hypertension. Therefore, KKS is an alternative pathway through which ACE can activates hypertension besides RAAS. This indicates that suppressing the RAAS pathway by inhibiting renin is not adequate at preventing hypertension. This limitation could possibly be overcome by co-administration of renin inhibitors and ACE inhibitors or developing a bioactive peptide with inherent potential to inhibit both renin and ACE enzymatic activities. Bioavailability is another challenge in the use of renin inhibitory peptides. For instance, the degree of enzymatic hydrolysis or microbial fermentation of protein is an important factor worth considering since continuous and uncontrolled enzymatic hydrolysis may result in a decrease or loss of bioactivity of the peptides (Daliri et al., 2017), and hence it is important to standardized and /or optimized the degree of enzymatic hydrolysis for each enzyme involved in the enzymatic hydrolysis (Agyei et al., 2016). Therefore, it is difficult to maintain the structure and integrity of bioactive peptide since they lose their stability after oral administration and therefore may not reach the target organs, tissues or cells in therapeutically effective forms (Hernández-Ledesma et al., 2014). Also bioactive peptides are easily degraded in the gut and therefore do not exhibit significant activity in the body when tested in vivo. This perhaps is a major challenge and setback in production and commercialization of bioactive peptides. However, this challenge can be overcome by using recombinant DNA technology or genetic engineering approaches to protects the peptides from digestion by endogenous proteases, thereby improving their bioavailability after oral administration (Kaspar and Reichert, 2013; Daliri et al., 2017).

\section{CONCLUSION}

Hypertension has been implicated as one of the major risk factor for cardiovascular disease (CVDs) and is amongst the leading cause of death worldwide. Renin catalyzes the rate-limiting step of the RAAS pathway which is crucial in the regulation of blood pressure. Perhaps, this activity makes renin a better target for management of hypertension than ACE. In this review, we highlighted the potential role of renin-inhibitory peptides towards ameliorating hypertension via RAAS pathway. Also this review demonstrated some limitations of renin inhibitors as sole therapy for management of hypertension and therefore, advocates the importance of adopting co-administration of both ACE and renin enzyme inhibitors as the most effective blood pressure control measure than individual alone.

\section{Conflict of interests}

The authors declare that they have no conflict of interest associated with this publication and there was no significant financial support for this work that could have influenced its outcome.

\section{ACKNOWLEDGEMENTS}

We would like to acknowledge Department of Biochemistry, Ahmadu Bello University, Zaria-Nigeria and also appreciate Dr. Suman Kapila of Animal Biochemistry Division National Dairy Research Institute Karnal, India for guidance, suggestions and words of encouragement towards writing of this review article.

\section{REFERENCES}

Addara, L., Bensouicib, C., Zenniaa, S.S.A., Harounc, S.B. \& Matia, A. (2019). Antioxidant, tyrosinase and urease inhibitory activities of camel $\alpha \mathrm{S}$-casein and its hydrolysate fractions, Small Ruminant Res., 173:30-35.

Aguilar-Toalá, J., Santiago-López, L., Peres, C., Peres, C., Garcia, H., Vallejo-Cordoba, B., González-Córdova, A. and Hernández-Mendoza, A. (2017). Assessment of multifunctional activity of bioactive peptides derived from fermented milk by specific Lactobacillus plantarum strains. J. Dairy Sci., 100:6575.

Agyei, D., Ongkudon, C.M., Wei, C.Y., Chan, A.S. and Danquah, M.K. (2016). Bioprocess challenges to the isolation and purification of bioactive peptides. Food Bioprod. Process, 98:244-256.

Aluko, R.E. (2019) Food protein-derived renin-inhibitory peptides: in vitro and in vivo properties. J. Food Biochem., 43:e12648.

Alvarado Y., Muro, C., Illescas, J., Díaz, M. and Riera, F. (2019). Encapsulation of Antihypertensive Peptides from Whey Proteins and Their Releasing in Gastrointestinal Conditions. Biomolecules, 9:164.

Ames, M.K., Atkins, C.E. and Pitt, B. (2019). The reninangiotensin-aldosterone system and its suppression. J. Vet. Intern. Med,. 33:363-382.

Bader, M. (2010). Tissue renin-angiotensin-aldosterone systems: targets for pharmacological therapy. Ann. Rev. Pharmacol. Toxicol., 50(1): 439-465.

Bader, M. and Ganten, D. (2008). Update on tissue reninangiotensin systems. J. Mol. Med., 86(6):615-621.

Bamdad, F., Shin, S.H., Suh, J., Nimalaratne, C. and Sunwoo, H. (2017). Anti-Inflammatory and Antioxidant Properties of Casein Hydrolysates Produced Using High Hydrostatic Pressure Combined with Proteolytic Enzymes. Molecules, 22:609.

Basilicata, M.J., Pepe, G., Adesso, S., Ostacolo, C., Sala, M., Sommella, E., Scala, M.C., Messore, A., Autore, G., Marzocco, S. and Campiglia, P. (2018). Antioxidant Properties of Buffalo-

FUDMA Journal of Sciences (FJS) Vol. 4 No. 2, June, 2020, pp 478 - 489 
Milk Dairy products: A $\beta$-Lg Peptide Released after Gastrointestinal Digestion of Buffalo Ricotta Cheese Reduces Oxidative Stress in Intestinal Epithelial Cells. Int. J. Mol. Sci., 19:1955.

Bedard, K. and Krause, K.H. (2007). The NOX family of ROSgenerating NADPH oxidases: physiology and pathophysiology. Physiol. Rev., 87:245-313.

Beuschlein, F. (2013). Regulation of aldosterone secretion: from physiology to disease. J. Endocrinol., 168(6):R85-R93.

Bleakley, S., Hayes, M., O’Shea, N., Gallagher, E. and Lafarga, T. (2017). Predicted release and analysis of novel ACE-I, renin, and DPP-IV inhibitory peptides from common oat (Avena sativa) protein hydrolysates using in silico analysis. Foods, 6:108.

Briet, M. and Schiffrin, E.L. (2010). Aldosterone: Effects on the kidney and cardiovascular system. Nat. Rev. Nephrol.. 6(5):261273.

Capriotti, A.L., Caruso, G., Cavaliere, C., Samperi, R., Ventura, S., Chiozzi, R.Z. and Lagana, A. (2015). Identification of potential bioactive peptides generated by simulated gastrointestinal digestion of soybean seeds and soy milk proteins. J. Food Compost. Anal., 44:205-213.

Chaudhari, D.D., Singh, R., Mallappa, R.H., Rokana, N., Kaushik, J.K., Bajaj, R., Batish, V.K. and Grover, S. (2017). Evaluation of casein \& whey protein hydrolysates as well as milk fermentates from Lactobacillus helveticus for expression of gut hormones. Indian J. Med. Res., 146:409-419.

Chen, Y., Meng, L., Shao, H. and Yu, F. (2013). Aliskiren vs. other antihypertensive drugs in the treatment of hypertension: A meta-analysis. Hypertens. Res., 36:252-261.

Ciau-Solis, N.A., Acevedo-Fernandez, J.J. and BetancurAncona, D. (2018) In vitro renin-angiotensin system inhibition and in vivo antihypertensive activity of peptide fractions from lima bean (Phaseolus lunatus L.). J. Sci. Food Agric., 98, 781786.

Daliri, E.B., Deog, H.O. and Byong, H.L. (2017). Bioactive peptides. Foods, 6:32.

Daliri, E.B., Lee, B.H. and Oh, D.H. (2016) Current perspectives on antihypertensive probiotics. Probiotics. Antimicrob. Proteins, 9(2): 91-101.

De-Mello, W.C. (2015) Chemical communication between heart cells is disrupted by intracellular renin and angiotensin ii: implications for heart development and disease. Front. Endocrinol. (Lausanne), 6:1-6.

De-Mello, W.C. and Frohlich, E.D. (2014). Clinical perspectives and fundamental aspects of local cardiovascular and renal Renin-Angiotensin systems. Front. Endocrinol. (Lausanne), 5:16.

Derkx, F.H.M, Schalekamp, M.P.A. and Schalekamp, M. A.D. (1987). Two-step prorenin-renin conversion. J. Biol. Chem., 262(6):2472-2477.

Duprez, D.A. (2006). Role of renin-angiotensin- aldosterone system in vascular remodeling and inflammation: A clinical review. J. Hypertens., 24:983-991.

Dzau, V.J., Bernstein, K., Celermajer, D, et al., (2001). The relevance of tissue angiotensin-converting enzyme: manifestations in mechanistic and endpoint data. Am. J. Cardiol., 88(9A):1L-20L.

Fernández-Musoles, R., Manzanares, P., Burguete, M.C., Alborch, E. and Salom, J.B. (2013). In vivo angiotensin Iconverting enzyme inhibition by long-term intake of antihypertensive lactoferrin hydrolysate in spontaneously hypertensive rats. Food Res. Int. 54:627-632.

Funder, J.W., Pearce, P.T., Smith, R. and Campbell, J. (1989). Vascular type I aldosterone binding sites are physiological mineralocorticoid receptors. Endocrinology, 125(4):2224-2226.

Funder, J.W., Pearce, P.T., Smith, R. and Smith, A.I. (1998). Mineralocorticoid action: target tissue specificity is enzyme, not receptor, mediated. Science, 242(4878):583-585.

Fyhrquist, F. and Saijonmaa, O. (2008). Renin-angiotensin system revisited. J. Intern. Med., 264:224-236.

García-Tejedor, A., Castelló-Ruiz, M., Gimeno-Alcañíz, J.V., Manzanares, P. and Salom, J.B. (2015). In vivo antihypertensive mechanism of lactoferrin-derived peptides: Reversion of Angiotensin-I- and Angiotensin II-induced hypertension in wister rats. J. funct. Foods, 15:294-300.

Ghazi , L. and Drawz, P. (2017). Advances in understanding the renin-angiotensin-aldosterone system (RAAS) in blood pressure control and recent pivotal trials of RAAS blockade in heart failure and diabetic nephropathy. F1000Res.,1(3):297.

Girgih, A.T., He, R. and Aluko, R.E. (2014). Kinetics and molecular docking studies of the inhibitions of angiotensin converting enzyme and renin activities by hemp seed (Cannabis sativa L.) peptides. J. Agric. Food Chem., 62:4135-4144. 
Girgih, A.T., Udenigwe, C.C., Li, H., Adebiyi, A.P. and Aluko, R.E. (2011). Kinetics of enzyme inhibition and antihypertensive effects of hemp seed (Cannabis sativa L.) protein hydrolysates. J. Am. Oil Chem. Soc., 88:1767-1774.

Guang, C., Phillips, R.D., Jiang, B., Milani, F. (2012). Three key proteases-Angiotensin-I-converting enzyme (ACE), ACE2 and Renin-within and beyond the renin-angiotensin system. Arch. Cardiovasc. Dis,.105:373-385.

Gul, W., Farooq, N., Anees, D., Khan, U. and Rehan, F. (2015). Camel Milk: A Boon to Mankind. Int. J. Res. Stud. Biosci., 3:23-29.

Hall, J.E. and Guyton, A.C. (2010). Role of the kidneys in longterm control of arterial pressure and in hypertension: the integrated system for arterial pressure regulation. Guyton and Hall Textbook of Medical Physiology. Philadelphia, PA: Elsevier Health Sciences 2010:213-228.

Harada, E., Yoshimura, M., Yasue, H., et al., (2001). Aldosterone induces angiotensin-converting-enzyme gene expression in cultured neonatal rat cardiocytes. Circulation, 104(2):137-139.

He, R., Malomo, S.A., Alashi, A., Girgih, A.T., Ju, X. and Aluko, R.E. (2013). Purification and hypotensive activity of rapeseed protein-derived renin and angiotensin converting enzyme inhibitory peptides. J. Funct. Foods, 5:781-789.

He, R., Yang, Y., Wang, Z., Xing, C., Yuan, J., Wang, L., Udenigwe, C., Ju, X. (2019). Rapeseed protein-derived peptides, LY, RALP, and GHS, modulates key enzymes and intermediate products of renin-angiotensin system pathway in spontaneously hypertensive rat. npj Sci. Food, 3:1.

Heitzer,T., Schlinzig, T., Krohn,K., Meinertz, T., and Münzel, T. (2001). Endothelial dysfunction, oxidative stress, and risk of cardiovascular events in patients with coronary artery disease," Circulation, 104(22):2673-2678.

Hernandez, L.M.R., de-Mejia, E.G. (2017). Bean peptides have higher in silico binding affinities than Ezetimibe for the Nterminal domain of cholesterol receptor Niemann-Pick C1 like1. Peptides, 90:83-89.

Hernández-Ledesma, B., Contreras, M., and Recio, I (2011) Antihypertensive peptides: Production, bioavailability and incorporation into foods. Adv. Colloid Interface Sci., 165:2335 .

Hernandez-Ledesma, B., Garcia-Nebot, M.J., Fernandez-Tome, S., Amigo, L. and Recio, I. (2014). Dairy protein hydrolysates: Peptides for health benefits. Int. Dairy J., 38:82-100.
Imig, J.D. (2004). ACE inhibition and bradykinin-mediated renal vascular responses: EDHF Involvement. Hypertension, 43(3): 533-5.

Jaisser, F. and Farman, N. (2015). Emerging roles of the mineralocorticoid receptor in pathology: toward new paradigms in clinical pharmacology. Pharmacol. Rev. 68(1):49-75.

Kaspar, A.A. and Reichert, J.M. (2013). Future directions for peptide therapeutics development. Drug Discov. Today, 18(1718):807-817.

Korczek, K., Tkaczewska, J. and Migdał, W. (2018). Antioxidant and Antihypertensive Protein Hydrolysates in Fish products- a Review. Czech J. Food Sci., 36 (3): 195-207.

Koyama, M., Hattori, S., Amano, Y., Watanabe, M. and Nakamura, K. (2014). Blood pressure -lowering peptides from neo-fermented buckwheat sprouts: A new approach to estimating ACE-inhibitory activity. PLoS ONE, 9, e105802.

Kumar, D., Chatli, M.K., Singh, R., Mehta, N. and Kumar, P. (2016). Enzymatic hydrolysis of camel milk casein and its antioxidant properties. Dairy Sci. Technol. 96:391-404.

Lafarga, T., O'Connor, P. and Hayes, M. (2014). Identification of novel dipeptidyl peptidase-IV and angiotensin-I-converting enzyme inhibitory peptides from meat proteins using in silico analysis. Peptides, 59:53-62.

Lafarga, T., Rai, D.K., O'Connor, P. and Hayes, M. (2015) A bovine fibrinogen-enriched fraction as a source of peptides with in vitro renin and angiotensin-I-converting enzyme inhibitory activities. J. Agric. Food Chem., 63:8676-8684.

Lafarga, T., Rai, D.K., O’Connor, P. and Hayes, M. (2016). Generation of bioactive hydrolysates and peptides from bovine hemoglobin with in vitro renin, angiotensin-I-converting enzyme and dipeptidyl peptidase-IV inhibitory activities. $J$. Food Biochem.,40:673-685.

Lammi, C., Zanoni, C., Calabresi, L. and Arnoldi, A. (2016). Lupin protein exerts cholesterol-lowering effects targeting PCSK9: From clinical evidences to elucidation of the in vitro molecular mechanism using HepG2 cells. J. Funct. Foods, 23:230-240.

Lassoued, I., Mora, L., Barkia, A., Aristoy, M., Nasr, M. and Toldra, F. (2015). Bioactive peptides identified in thorn-back ray skin's gelatin hydrolysates by proteases from Bacillus subtilis and Bacillus amyloliquefaciens. J. Proteomics, 128:817.

FUDMA Journal of Sciences (FJS) Vol. 4 No. 2, June, 2020, pp 478 - 489 
Li, H. and Aluko, R.E. (2010). Identification and inhibitory properties of multifunctional peptides from pea protein hydrolysate. J. Agric. Food Chem., 58:11471-11476.

Li, H., Prairie, N., Udenigwe, C.C., Adebiyi, A.P., Talappia, P.S., Aukeema, H.M., Jones, P.J., Aluko, R.E. (2011). Blood pressure lowering effect of a pea protein hydrolysate in hypertensive rats and humans. J. Agric. Food Chem., 59:98549860 .

Lin, H., Alashi, A.M., Aluko, R.E., Pan, B.S. and Chang, Y. (2017). Antihypertensive properties of tilapia (Oreochromis spp.) frame and skin enzymatic protein hydrolysates. Food Nutr. Res. 61:1,1391666.

Lin, K., Zhang, L., Han, X., Xin, L., Meng, Z., Gong, P. and Cheng, D. (2018). Yak milk casein as potential precursor of angiotensin-I-converting enzyme inhibitory peptides based on in silico proteolysis. Food chem., 254:340-347.

Liu, L., Li, S., Zheng, J., Bu., T.,He., G., Wu, J. (2019). Safety considerationson food proteinderived bioactive peptides. Trends Food Sci. Technol. 96:199-207.

Mada, S.B., Reddi, S., Kumar, N., Kumar, R., Kapila, S., Kapila, R., Trivedi, R., Karvande, A. and Ahmad, N. (2017a). Antioxidative peptide from milk Exhibits antiosteopenic effects through inhibition of oxidative damage and bone-resorbing cytokines in ovariectomized rats. Nutrition, 43-44:21-31.

Mada, S.B., Reddi, S., Kumar, N., Kapila, S. and Kapila, R. (2017b).Protective effects of caseinderived peptide VLPVPQK against hydrogen peroxide-induced dysfunction and cellular oxidative damage in rat osteoblastic cells. Hum. Exp. Toxicol., 36(4) $1-14$.

Mada, S.B., Reddi, S., Kumar, N., Vij, R., Yadav, R., Kapila, S. and Kapila R (2018). Casein-derived antioxidative peptide prevents oxidative stress-induced dysfunction in osteoblast cells. PharmaNutrition, 6:169-179.

Mada, S.B, Ugwu, C.P. and Abarshi, M.M. (2019). Health Promoting Effects of Food-Derived Bioactive Peptides: A Review. Int. J. Pept. Res. Ther. 19(4):1573-3149.

Martin, M., Kopaliani, I., Jannasch, A., Mund, C., Todorov, V., Henle, T. and Deussen, A. (2015). Antihypertensive and cardioprotective effects of the dipeptide isoleucine-tryptophan and whey protein hydrolysate. Acta Physiol. 215, 167-176.

Marzolla, V., Armani, A., Feraco, A., De-Martino, M.U., Fabbri, A., Rosano, G. and Caprio, M. (2014). Mineralocorticoid receptor in adipocytes and macrophages: a promising target to fight metabolic syndrome. Steroids, 91:4653.

Marzolla, V., Armani, A., Zennaro, M.C., Cinti, F., Mammi, C., Fabbri, A., Rosano, G.M., Caprio, M. (2012). The role of the mineralocorticoid receptor in adipocytes biology and fat metabolism. Mol. Cell Endocrinol. 350(2):281-288.

Mirzaei, M., Mirdamadi, S., Ehsani, M.R. and Aminlari, M. (2018). Production of antioxidant and ACE-inhibitory Peptides from Kluyveromyces marxianus protein hydrolysates: Purification and molecular docking. J. food drug anal., 26 (2):696-705.

Mohanty, D.P., Mohapatra, S., Misra, S. and Sahu, P.S. (2016). Milk derived bioactive peptides and their impact on human health-A review. Saudi J. Biol. Sci., 23(5):577-583.

Nawaz, K.A.A., David, S.M., Murugesh, E., Thandeeswaran, M., GopikrishnanKiran, K., Mahendran, R. et al. (2017). Identification and in silico characterization of a novel peptide inhibitor of angiotensin converting enzyme from pigeon pea (Cajanuscajan). Phytomedicine, 09:013.

Onuh, J.O., Girgih, A.T., Aluko, R.E. and Aliani, M. (2013). Inhibitions of renin and angiotensin converting enzyme activities by enzymatic chicken skin protein hydrolysates. Food Res. Int., 53:260-267.

Onuh, J.O., Girgih, A.T., Malomo, S.A., Aluko, R.E., Aliani, M. (2015). Kinetics of in vitro renin and angiotensin converting enzyme inhibition by chicken skin protein hydrolysates and their blood pressure lowering effects in spontaneously hypertensive rats. J Funct Foods, 14:133-143.

Onuh, J.O., Girgih, A.T., Nwachukwu, I.D., Levari-Shariati, S., Raj, P., Netticadan, T. and Aliani, M. (2016). A metabolomics approach for investigating urinary and plasma changes in spontaneously hypertensive rats (SHR) fed chicken skin protein hydrolysates diets. J. Funct. Foods, 22:20-33.

Pachaiappan, R., Tamboli, E., Acharya, A., Su, C., Gopinath, S.C.B., Chen, Y., Velusamy, P. (2018). Separation and identification of bioactive peptides from stem of Tinospora cordifolia (Willd) Miers. PLoS ONE 13(3): e0193717.

Palaniswamy, M., Angayarkanni, J., Nandhini, B. (2012). Angiotensin converting enzyme inhibitory activity and antioxidant properties of goat milk hydrolysates. Int. J. Pharm. Pharm. Sci., 4:367-370.

Panth, N., Paudel, K.R., Parajuli, K. (2016). Reactive Oxygen Species: A Key Hallmark of Cardiovascular Disease-A review. Adv. Med., 9152732. 
Paudel, K.R., Lee, U.W., Kim, D.W. (2016). Chungtaejeon, a Korean fermented tea, prevents the risk of Atherosclerosis in rats fed a high-fat atherogenic diet. J. Integr. Med. 14(2):134142 .

Reddi, S., Kumar, N., Vij, R., Mada, S. B., Kapila, S. and Kapila, R. (2016). Akt drives buffalo casein-derived novel peptide-mediated osteoblast differentiation.. J. Nutr. Biochem., 38:134-144.

Reddi, S., Mada, S. B., Kumar, N., Kumar, R., Ahmad, N., Karvande, A. and Trivedi, R. (2018). Antiosteopenic effect of buffalo milk casein-derived peptide (NAVPITPTL) in ovariectomized rats. Int. J. Pept. Res. Ther., 25(3):1147-1158.

Roberts, P. R., Burney, J. D., Black, K. W. and Zaloga, G. P. (1999). Effect of chain length on absorption of biologically active peptides from the gastrointestinal tract. Commons. Digestion, 60(4):332-337.

Seelinger, E., Wronski, T., Ladwig, M. et al., (2005). The "body fluid pressure control system" relies on the renin-angiotensinaldosterone system: balance studies in freely moving dogs. Clin. Exp. Pharmacol. Physiol., 32(5-6):394-399.

Udenigwe, C.C., Li, H., Aluko, R.E. (2012). Quantitative structure-activity relationship modeling of renin-inhibiting dipeptides. Amino Acids, 42:1379-1386.

Udenigwe, C.C., Lin, Y.S., Hou, W.C., Aluko, R.E. (2009). Kinetics of the inhibition of renin and angiotensin I-converting enzyme by flaxseed protein hydrolysate fractions. J. Funct. Foods, 1:199-207.

Ugwu, C.P., Abarshi, M.M., Mada, S.B., Sanusi, B. and Nzelibe, H.C. (2019). Camel and Horse Milk Casein Hydrolysates Exhibit Angiotensin Converting Enzyme Inhibitory and Antioxidative Effects In vitro and In silico. Int. J. Pept. Res. Ther., 19(4):1573-3139.

Ullian, M.E. and Fine, J.J. (1994). Mechanisms of enhanced angiotensin. J. Cell Physiol. 161(2):201-208.

Ullian, M.E., Hutchison, F.N., Hazen-Martin, D.J. and Morinelli, T.A. (1993). Angiotensin II-aldosterone interactions on protein synthesis in vascular smooth muscle cells. Am J Physiol. 264:C1525-C1531.
Ullian, M.E., Schelling, J.R., Linas, S.L. (1992). Aldosterone enhances angiotensin II receptor binding and inositol phosphate responses. Hypertension, 20 (1):67-73.

Vincent-Onabajo, G.O., Adaji, J.O., and Umeonwuka, C.I. (2017). Prevalence of undiagnosed Hypertension among traders at a regional market in Nigeria. Ann. Med. Health Sci. Res. 7: 97-101.

Wang, X., Chen, H., Fu, X., Li, S., Wei, J. (2017). A novel antioxidant and ace inhibitory peptide from rice bran protein: Biochemical characterization and molecular docking study. LWT-Food Sci. Technol.,75:93-99.

Yahya, M.A., Alhaj, O.A. and Al-Khalifa, A.S. (2017). Antihypertensive effect of fermented skim camel (Camelus dromedaries) milk on spontaneously hypertensive rats. Nutr. Hosp. 34(2):416-421.

Yang, Y., He, H., Wang, F., Ju, X., Yuan, J., Wang, L., Aluko, R.E. and He, R. (2017). Transport of ACE and renin dual inhibitory peptides LY, RALP and TF across CaCo-2 cell monolayers. J. Funct. Foods 35:303-314.

Yu, Z., Yin, Y., Zhao, W., Chen, F. and Liu, J. (2014). Antihypertensive effect of angiotensin converting enzyme inhibitory peptide RVPSL on spontaneously hypertensive rats by regulating gene expression of the renin-angiotensin system. J. Agric. Food Chem. 62:912-917.

Zhou, H. X. and Pang, X. (2018). Electrostatic Interactions in Protein Structure, Folding, Binding, and Condensation. Chem. Rev.,118(4):1691-1741.

Zou, T., He, T., Li, H., Tang, H. and Xia, E. (2016). The Structure-Activity Relationship of the Antioxidant Peptides from Natural Proteins. Molecules, 21:72. 